\title{
Little Association between Intracranial Arterial Stenosis and Lacunar Stroke
}

\author{
Joanna M. Wardlaw ${ }^{a}$ b Fergus N. Doubal ${ }^{a}$ Elizabeth Eadie ${ }^{a}$ \\ Francesca Chappell $^{\mathrm{a}}$ Kirsten Shuler $^{\mathrm{a}, \mathrm{b}}$ Vera Cvoro $^{\mathrm{a}}$ \\ aScottish Imaging Network, a Platform for Scientific Excellence (SINAPSE) Collaboration, SFC Brain Imaging \\ Research Centre, and ${ }^{b}$ Division of Clinical Neurosciences, University of Edinburgh, Edinburgh, UK
}

\section{Key Words}

Stroke $\cdot$ Lacunar stroke $\cdot$ Small-vessel disease .

Middle cerebral artery $\cdot$ Stenosis $\cdot$ Atheroma •

Transcranial Doppler ultrasound

\begin{abstract}
Atheromatous middle cerebral artery (MCA) stenosis could cause lacunar stroke by occluding lenticulostriate artery origins, but atheroma is common, and previous studies lacked suitable controls. We aimed to determine if intracranial atheroma was more common in lacunar than in cortical ischaemic stroke. We recruited patients with lacunar stroke and controls with mild cortical stroke, confirmed the stroke subtype with magnetic resonance imaging and used transcranial Doppler ultrasound imaging to record flow velocity and focal stenoses in the basal intracranial arteries 1 month after stroke. We compared ipsi- and contralateral MCA mean flow velocities between stroke subtypes and tested for associations using linear mixed models. Amongst 67 lacunar and 67 mild cortical strokes, mean age 64 and 67 years, respectively, we found no difference in MCA mean flow velocity between cortical and lacunar patients. Increasing age and white matter lesion scores were independently associated with lower MCA flow velocities $\left(0.2 \mathrm{cms}^{-1}\right.$ fall in velocity per year increase in age, $p=0.045 ; 3.75 \mathrm{cms}^{-1}$ fall in flow velocity per
\end{abstract}

point increase in white matter lesion score, $p=0.004)$. We found no intracranial arterial stenoses. MCA atheromatous stenosis is unlikely to be a common cause of lacunar stroke in white populations. Falling velocities with increasing white matter lesion scores may reflect progressive brain tissue loss leaving less tissue to supply.

Copyright $\odot 2010$ S. Karger AG, Basel

\section{Introduction}

Lacunar ischaemic stroke is a specific subtype of ischaemic stroke due to a small ( $<2 \mathrm{~cm}$ diameter) infarct in the cerebral hemispheric deep grey matter or white matter or the brainstem. The cause is not well understood [1, 2]. Possible aetiologies include atherothromboembolism from the carotid or intracranial arteries, atheromatous stenosis encroaching on the ostia of the lenticulostriate arteries, or an intrinsic small penetrating arteriolar disease [3]. Different aetiologies may be more prevalent in patients of different ethnic origins. For example, stroke secondary to middle cerebral artery (MCA) atheromatous stenosis is said to be common in Chinese Asian, African American and Mediterranean peoples [4-6] but appears to be uncommon in other populations, such as white northern Europeans [7].

Prof. J. Wardlaw

Division of Clinical Neuroscience

Western General Hospital

Crewe Road, Edinburgh EH4 2XU (UK)

Tel. +44 131537 2943, Fax +44 131332 5150, E-Mail Joanna.wardlaw@ed.ac.uk 
Previous studies of MCA atheroma in lacunar stroke have either not categorized the stroke subtype [8], included very few patients with lacunar stroke [9] or did not include a control group of patients with an alternative type of ischaemic stroke [10]. Some studies may have confused small striatocapsular infarcts (which may be more likely to have underlying atheroma as a cause) with true lacunar stroke. Yet others have suggested that intracranial arterial stenosis is a predictor of any ischaemic event, not just of lacunar stroke [11-14]. In the Rotterdam Scan Study, higher MCA velocities (but still within the normal range) were associated with stroke of unspecified type during follow-up [8], and arterial stiffness was strongly related to atherosclerosis at various sites [15], suggesting that intracranial atheroma, arterial stiffness and related features of atheroma may simply be common in older populations and not necessarily specifically related to lacunar stroke.

We examined the intracranial arteries in patients with lacunar ischaemic stroke and controls with cortical ischaemic stroke (to represent a definite larger artery ischaemic stroke mechanism such as atherothrombosis or cardioembolism), recorded the major intracranial arterial velocities and identified any focal stenosis or other arterial abnormalities.

\section{Patients and Methods}

Patients and Clinical Assessment

We prospectively recruited patients who presented with clinical features of acute lacunar stroke and controls with mild cortical stroke, as consecutively as possible, at a large teaching hospital between January 2005 and July 2007. We excluded patients who were medically unstable, had contraindications to magnetic resonance (MR) imaging or who were unwilling to participate. All patients were assessed by a trained stroke physician who determined the clinical stroke syndrome according to the Oxfordshire Community Stroke Project classification [16], a risk-factor-free classification that avoids confounding [17].

Mild cortical stroke was defined as equivalent to a partial anterior circulation stroke syndrome [16]. Lacunar stroke clinical syndrome was defined as pure motor weakness and/or sensory loss of face and arm, arm and leg or all 3, ataxic hemiparesis or clumsy hand dysarthria syndrome according to the Oxfordshire Community Stroke Project Classification [16].

All patients underwent investigations for stroke cause (carotid Doppler ultrasound, electrocardiogram, blood tests, brain imaging and other tests as indicated). We recorded vascular risk factors (diabetes, hypertension, atrial fibrillation, previous stroke/transient ischaemic attack, ischaemic heart disease, carotid stenosis as described previously [18]), drug treatment prior to the stroke and the National Institute for Health Stroke Score (NIHSS) at presentation. Diabetes and hypertension referred to a physician diagno- sis of these plus/minus hypoglycaemic or antihypertensive medication as appropriate.

The study was approved by the local research ethics committee and all patients gave written informed consent.

\section{Diagnostic MR Imaging}

The patients had diagnostic MR imaging at presentation to identify the site of the recent infarct, any previous vascular lesion and to quantify white matter lesions (WMLs). All brain imaging was performed on a 1.5-tesla MR scanner (Signa LX; General Electric, Milwaukee, Wisc., USA) with $22 \mathrm{mTm}^{-1}$ maximum strength gradients. Sagittal $\mathrm{T}_{1}$-weighted and axial diffusionweighted, $\mathrm{T}_{2}$-weighted, fluid-attenuated inversion recovery (FLAIR) and gradient echo sequences were performed as described previously [18]. A consultant neuroradiologist noted the presence and location of any acute ischaemic stroke lesion (high signal on diffusion imaging, low signal on apparent diffusion coefficient map), any old ischaemic stroke lesions (high or low signal on FLAIR, high signal on $\mathrm{T}_{2}$-weighted imaging, no signal change on diffusion imaging/apparent diffusion coefficient map), old hemorrhages (low signal on gradient echo imaging), and coded periventricular and deep white matter lesions [19] in the FLAIR images, and enlarged perivascular spaces (EPVS) in the basal ganglia and centrum semiovale in the $\mathrm{T}_{2}$-weighted images using a scale previously developed by our group [20]. All image assessment was performed blind to all patient details.

Lacunar infarcts were defined as acute ischaemic lesions (as above), rounded, of $<2 \mathrm{~cm}$ diameter in the basal ganglia, internal capsule, centrum semiovale or brainstem. Cortical lesions were defined as acute ischaemic lesions (as above) which involved cortical and adjacent subcortical tissue in a distribution consistent with a known cortical arterial branch territory. The final stroke subtype classification was determined from the Oxfordshire Community Stroke Project clinical subtype [16] and the recent infarct site (lacunar or cortical) on diagnostic MR imaging. Where the clinical and imaging stroke subtypes differed, the final diagnosis was determined by the imaging lesion type [21]. In the absence of an acute stroke lesion on imaging, the clinical subtype was used but all cases were discussed by a reference standard expert panel of stroke physicians and neuroradiologists with all available diagnostic information, to assign a final diagnosis.

\section{Transcranial Doppler Examination}

Transcranial Doppler (TCD) imaging was performed at least a month after the index stroke to allow any acute arterial velocity changes associated with the acute stroke (e.g. reduced flow due to branch occlusion, increased flow due to acute postrecanalization hyperaemia) to have resolved. A trained neurosonographer or consultant neuroradiologist performed the TCD examination through the temporal bone window, blind to the stroke subtype, brain imaging and clinical features. We used a Siemens Elegra Doppler ultrasound imaging machine (Siemens, Erlangen, Germany) with a variable frequency $2.5 \mathrm{MHz}$ linear-phased array probe operating at $1.5-2 \mathrm{MHz}, 100 \%$ output, 3 frames per second, pulse repetition frequency $1,102 \mathrm{~Hz}$. We used colour and power Doppler imaging settings to ensure correct vessel identification. We insonated the terminal internal carotid, middle, anterior and posterior cerebral (ICA, MCA, ACA, PCA, respectively) and basilar arteries, and anterior and posterior communicating arteries at standard depths. We recorded from the proximal and distal 
MCA segments at 55-65 and 35-45 mm depth from the temporal skin surface, respectively. During the examination, we noted the presence of focal stenoses, reduced flow in an artery on one side of the head compared with the other, the direction of flow in the communicating arteries and A1 and P1 segments of the ACA and PCAs, respectively. Focal stenosis was diagnosed as focal elevation in peak systolic flow velocity to $>120 \mathrm{cms}^{-1}$ or mean velocity to $>80 \mathrm{cms}^{-1}$, or a difference between the ipsi- and contralateral mean velocities of $>30 \mathrm{cms}^{-1}$, with turbulence/spectral broadening, +/- vessel wall vibration [22]. Velocity data were processed offline (blind to all patient details) to obtain peak and time-averaged mean flow velocities and pulsatility index in all arteries from which it had been possible to obtain velocity readings. $\mathrm{Pa}$ tients with limited or no bone window, and absent arteries where the bone window was good, were also noted.

\section{Statistical Analysis}

We tested for differences between the lacunar and cortical subgroups in their basic demographic and clinical data, blood velocities in the distal and proximal MCAs using $\chi^{2}$ and Wilcoxon tests as appropriate. We focused on the MCA velocity data for multivariate analysis as most data were available for the MCAs and lacunar and mild cortical stroke most commonly occur in the MCA territory. We analyzed the MCA velocity data using a linear mixed model which allowed data from the ipsilateral and contralateral sides of each patient to contribute to the same analysis and also to include all patients even if there were some missing variables. We tested whether the MCA velocities were related to stroke subtype, age, sex, diabetes, hypertension, the WML score (expressed as the mean of periventricular and deep white matter lesions) and EPVS (expressed as the total of basal ganglia + centrum semiovale score). The validity of the statistical assumptions underlying use of the linear mixed model was checked and found to be satisfactory (i.e. the linear mixed model provided a reasonable description of the data). As WML score and EPVS were strongly correlated, we removed EPVS from the analysis as it added very little extra information over and above that given by the WML score.

\section{Results}

We recruited 140 patients but 6 had no bone window, leaving 67 with lacunar and 67 with cortical stroke. Virtually all of the 134 patients were white. The patients with cortical ischaemic stroke were slightly older than the lacunar stroke patients (70 vs. 64.5 years, $\mathrm{p}=0.01$, Wilcoxon) with no difference in stroke severity (NIHSS median both 1).

A larger proportion of patients had atrial fibrillation in the cortical than in the lacunar stroke subgroup (11.9 vs. $3.0 \%, p=0.049$ ). Also more cortical stroke patients had ischaemic heart disease ( 22.4 vs. $11.9 \%$ ) and $\geq 50 \%$ ipsilateral carotid stenosis (19.3 vs. 9.8\%) but these latter 2 did not reach statistical significance (table 1). There was no difference in the proportion with previous stroke or transient ischaemic attack, peripheral vascular disease, hypertension, or old stroke lesions, WMLs or EPVS on MRI imaging.

TCD was performed at a median of 44 or 48 days after lacunar or cortical stroke, respectively $(p=0.47)$. There was no difference in the mean flow velocities in the proximal or distal MCAs, on the side ipsi- or contralateral to the side of the index stroke, between the lacunar and cortical stroke patients (table 2). No patients had focal high velocity areas in the middle cerebral arteries on either side to suggest focal MCA stenosis.

In the multivariate analysis with linear mixed modelling adjusted for stroke subtype, age, sex, diabetes, hypertension and WML score, we found that increasing age, female sex and increasing WML scores were significantly associated with lower MCA flow velocities, and hypertension was related to higher velocities, but there was no association with stroke subtype or diabetes (table 3). A similar pattern was observed in both proximal and distal MCAs. On average, in the proximal MCA, for a 1-point increase in WML score, the MCA flow velocity fell by 3.75 $\mathrm{cms}^{-1}(\mathrm{p}=0.004)$, females had lower flow velocities than males by $5.92 \mathrm{cms}^{-1}$, the flow velocity fell by $0.20 \mathrm{cms}^{-1}$ for every 1-year increase in age, and hypertensive patients had a $3.99 \mathrm{cms}^{-1}$ higher velocity than those without hypertension. Interestingly, although the association did not reach conventional significance, the MCA velocities in the lacunar subgroup were on average $3.57 \mathrm{cms}^{-1}$ lower than in the cortical subgroup in the adjusted analysis $(\mathrm{p}=0.07)$.

The unadjusted analyses (not shown) were little different except that there was no association with hypertension (this can occur if hypertension has an inverse relationship with one of the other variables), the relationship with increasing age was stronger and the suggestion of a possible association with stroke subtype disappeared. The little variation between adjusted and unadjusted analyses suggests that the differences in other baseline characteristics are not affecting these results. The small differences between the adjusted and unadjusted results and the reasonable performance of the linear mixed model in describing these data suggest that the relationship between velocity and sex, age and WML score is real.

\section{Discussion}

In this group of carefully characterized stroke patients, we found no evidence of intracranial arterial stenosis associated with lacunar stroke. There was no evi- 
Table 1. Demographic features of the 67 patients with cortical, and 67 with lacunar stroke subtypes included in the study

\begin{tabular}{|c|c|c|c|c|c|c|c|c|c|}
\hline & \multicolumn{8}{|c|}{ Stroke subtype } & \multirow{3}{*}{$\begin{array}{l}\text { Test } \\
\text { p value } \\
\text { Wilcoxon }\end{array}$} \\
\hline & \multicolumn{4}{|c|}{ cortical } & \multicolumn{4}{|c|}{ lacunar } & \\
\hline & $\mathrm{n}$ & median & min., max. & IQR & $\mathrm{n}$ & median & min., max. & IQR & \\
\hline Age, years & 67 & 70.1 & $40.9,91.9$ & $60.6-75.3$ & 67 & 64.5 & $36.3,85.9$ & $55.2-71.2$ & 0.011 \\
\hline \multirow[t]{2}{*}{ NIHSS } & 66 & 1 & 0,7 & $0-2.0$ & 67 & 1 & 0,9 & $0-2.0$ & 0.37 \\
\hline & $\mathrm{N}$ & $\mathrm{n}$ & $\%$ & & $\mathrm{~N}$ & $\mathrm{n}$ & $\%$ & & $\chi^{2}$ \\
\hline \multicolumn{10}{|l|}{ Sex } \\
\hline F & 67 & 9 & 13.4 & & 67 & 17 & 25.4 & & 0.081 \\
\hline $\mathrm{M}$ & & 58 & 86.6 & & & 50 & 74.6 & & \\
\hline \multicolumn{10}{|l|}{ TIA } \\
\hline Yes & 67 & 7 & 10.4 & & 66 & 5 & 7.6 & & 0.56 \\
\hline No & & 60 & 89.6 & & & 61 & 92.4 & & \\
\hline \multicolumn{10}{|c|}{ Previous stroke } \\
\hline Yes & 67 & 7 & 10.4 & & 66 & 2 & 3.0 & & 0.089 \\
\hline No & & 60 & 89.6 & & & 64 & 97.0 & & \\
\hline \multicolumn{10}{|l|}{ IHD } \\
\hline Yes & 67 & 15 & 22.4 & & 67 & 8 & 11.9 & & 0.11 \\
\hline No & & 52 & 77.6 & & & 59 & 88.1 & & \\
\hline \multicolumn{10}{|l|}{ PVD } \\
\hline Yes & 67 & 4 & 6.0 & & 67 & 2 & 3.0 & & 0.40 \\
\hline No & & 63 & 94.0 & & & 65 & 97.0 & & \\
\hline \multicolumn{10}{|l|}{ Diabetes } \\
\hline Yes & 67 & 6 & 9.0 & & 67 & 11 & 16.4 & & 0.19 \\
\hline No & & 61 & 91.0 & & & 56 & 83.6 & & \\
\hline \multicolumn{10}{|c|}{ Hypertension } \\
\hline Yes & 67 & 41 & 61.2 & & 67 & 35 & 52.2 & & 0.30 \\
\hline No & & 26 & 38.8 & & & 32 & 47.8 & & \\
\hline \multicolumn{10}{|l|}{$\mathrm{AF}$} \\
\hline Yes & 67 & 8 & 11.9 & & 67 & 2 & 3.0 & & 0.049 \\
\hline No & & 59 & 88.1 & & & 65 & 97.0 & & \\
\hline \multicolumn{10}{|c|}{ Carotid stenosis $>50 \%$} \\
\hline Yes & 57 & 11 & 19.3 & & 61 & 6 & 9.8 & & 0.14 \\
\hline No & & 46 & 80.7 & & & 55 & 90.1 & & \\
\hline \multicolumn{10}{|c|}{ Old stroke lesion on imaging } \\
\hline Yes & $67^{\circ}$ & 24 & 35.8 & & 67 & 24 & 35.8 & & $>0.999$ \\
\hline No & & 43 & 64.2 & & & 43 & 64.2 & & \\
\hline
\end{tabular}

$\mathrm{IQR}=$ Interquartile range; TIA = transient ischaemic attack; IHD = ischaemic heart disease; PVD = peripheral vascular disease; $\mathrm{AF}=$ atrial fibrillation.

dence of any arterial velocity elevation to suggest the presence of a focal MCA stenosis in lacunar or cortical stroke patients. We found significant associations between lower MCA flow velocities and increasing WMLs and increasing age and between higher velocities and hypertension. These analyses were robust, with similar results for both adjusted and unadjusted analyses, and in the proximal and distal MCAs. Cortical stroke patients had more large artery atheroma outside the head (more carotid stenosis, ischaemic heart disease) and more embolic sources (atrial fibrillation) than did lacunar stroke patients. Our results would therefore suggest that intracranial large artery atheroma is unlikely to be a common cause of lacunar or of cortical stroke, at least in white populations.

The strengths of our study are the very careful clinical and imaging diagnosis of stroke subtype to avoid misclassifying lacunar and cortical stroke [23], the blinding of 
Table 2. MCA velocity in cortical and lacunar ischaemic stroke patients

\begin{tabular}{|c|c|c|c|c|c|}
\hline Artery & Stroke subtype & $\mathrm{n}$ & Median & IQR & $\mathrm{p}$ value \\
\hline \multirow[t]{2}{*}{ Ipsilateral proximal MCA } & cortical & 61 & 41.0 & $32.0-53.0$ & \multirow[t]{2}{*}{0.13} \\
\hline & lacunar & 64 & 38.5 & $31.0-49.0$ & \\
\hline \multirow[t]{2}{*}{ Contralateral proximal MCA } & cortical & 63 & 41.0 & $35.0-49.0$ & \multirow[t]{2}{*}{0.92} \\
\hline & lacunar & 61 & 42.0 & $34.0-50.0$ & \\
\hline \multirow[t]{2}{*}{ Ipsilateral distal MCA } & cortical & 59 & 39.0 & $32.0-48.0$ & \multirow[t]{2}{*}{$>0.99$} \\
\hline & lacunar & 56 & 39.5 & $30.0-49.0$ & \\
\hline \multirow[t]{2}{*}{ Contralateral distal MCA } & cortical & 58 & 42.0 & $35.0-49.0$ & \multirow[t]{2}{*}{0.38} \\
\hline & lacunar & 60 & 39.5 & $31.0-51.0$ & \\
\hline
\end{tabular}

Total $\mathrm{n}=130$ patients (124 contributing to both distal and proximal MCA, and 6 to proximal only, spectra adequate for determination of velocity not obtained from 4 patients).

Table 3. Multivariate analysis to examine association between MCA flow velocity, stroke subtype, demographic and risk factor variables

a Proximal MCA - adjusted analysis (variable adjusted for all others in the table)

\begin{tabular}{llll}
\hline Variable & $\begin{array}{l}\text { Estimate of } \\
\text { change per } \\
\text { unit change }\end{array}$ & $\begin{array}{l}\text { 95\% confidence } \\
\text { limits }\end{array}$ & $\begin{array}{l}\mathrm{p} \\
\text { value }\end{array}$ \\
& & & \\
\hline $\begin{array}{c}\text { Lacunar vs. cortical } \\
\quad \text { cortical is baseline) }\end{array}$ & -3.57 & $-7.39,0.25$ & 0.067 \\
$\begin{array}{l}\text { Age } \\
\text { Sex (F is baseline) }\end{array}$ & -0.20 & $-0.39,-0.0045$ & 0.045 \\
$\begin{array}{l}\text { Diabetic status } \\
\quad(\mathrm{N} \text { is baseline) }\end{array}$ & -5.92 & $-10.72,-1.12$ & 0.016 \\
$\begin{array}{l}\text { Hypertension } \\
\quad(\mathrm{N} \text { is baseline) }\end{array}$ & -2.55 & $-8.05,2.95$ & 0.36 \\
$\begin{array}{l}\text { White matter lesion } \\
\text { score }\end{array}$ & -3.75 & $0.080,7.89$ & 0.046 \\
\hline
\end{tabular}

b Distal MCA - adjusted analysis (variable adjusted for all others in the table)

\begin{tabular}{llll}
\hline $\begin{array}{l}\text { Lacunar vs. cortical } \\
\quad(\text { cortical is baseline })\end{array}$ & -2.51 & $-6.82,1.79$ & 0.25 \\
Age & -0.14 & $-0.35,0.078$ & 0.21 \\
Sex (F is baseline) & -7.07 & $-12.45,-1.68$ & 0.011 \\
$\begin{array}{l}\text { Diabetic status } \\
\quad(\mathrm{N} \text { is baseline) }\end{array}$ & -4.90 & $-10.92,1.11$ & 0.11 \\
$\begin{array}{l}\text { Hypertension } \\
\quad(\mathrm{N} \text { is baseline) }\end{array}$ & 4.13 & $-0.20,8.46$ & 0.061 \\
$\begin{array}{l}\text { White matter lesion } \\
\quad \text { score }\end{array}$ & -3.23 & $-6.09,-0.37$ & 0.027 \\
\hline
\end{tabular}

$\mathrm{F}=$ Female; $\mathrm{N}=$ normal. the TCD operator and of the assessment of velocities to stroke subtype, the use of both subjective assessments of arteries and actual velocity readings, and the adjustment for multiple variables. We used TCD imaging to ensure that we had correctly identified and not missed any arteries. TCD is an accurate method of detecting intracranial arterial stenoses [24] and provides accurate and rapid assessment of arterial patency in acute ischaemic stroke $[25,26]$.

The weaknesses are the relatively small sample size so that we may have missed a minor difference in velocity between the lacunar and cortical subtypes, although this sample size was adequate to demonstrate a difference in blood-brain barrier permeability [18] and plasma biomarkers [27] between lacunar and cortical stroke patients. TCD may miss stenoses of $<50 \%$ due to arteriolar wall remodelling, but most would not consider stenoses of $<50 \%$ to be severe enough to cause stroke. Our analysis would suggest that the lacunar stroke patients have slightly lower velocities throughout the MCA (but still within the normal range), than do the cortical patients, further reducing the possibility of a stenosis. We did not take a detailed ethnic history, but our population are ethnically largely white northern Europeans.

The literature on the prevalence of intracranial atheromatous stenosis and stroke subtype is somewhat conflicting and difficult to interpret due to lack of standardization of assessment methods. Intracranial artery stenosis is said to be more frequent in Asian, African, Spanish and Portuguese populations with stroke $[4,6,28]$, although this may partly reflect differences in case ascertainment methods. Intracranial artery stenosis was present in $49 \%$ of the Hong Kong Chinese [5] and 12\% of the Koreans [29] and was associated with an increased risk of 
future stroke (subtype unspecified) [14] and death [5] Even in Asian populations where the prevalence of MCA stenosis is said to be high, only $18 \%$ [14] or $36 \%$ [10] of the patients with small subcortical ischaemic stroke had ipsilateral MCA stenosis, although we do not know what proportion of other stroke subtypes had ipsilateral MCA stenosis. So it is possible that, as with ICA origin stenosis in lacunar stroke [30], MCA stenosis could be coincidental. Unfortunately, many studies of intracranial arterial stenosis in Western populations were small or contained few patients with lacunar stroke $[9,31]$, recorded velocities only in the acute phase of stroke $[24,26]$, or did not differentiate stroke subtypes or ethnic origins [9], making the present study the largest to focus specifically on lacunar versus cortical stroke. Lyrer et al. [7] screened 4,382 Swiss patients with stroke to identify 20 patients with MCA stenosis and ipsilateral stroke (0.4\%), of which 17 were cortical or large striatocapsular and only 5 looked like lacunar ischaemic stroke on imaging. One autopsy study of 339 patients dying following stroke found numerous intracranial plaques and stenoses, but these were thought to be causative of the stroke in only 15 patients (5.8\%), with little information on stroke subtype [12]. A further analysis of patients with MCA territory stroke in the same autopsy database indicated that MCA stenosis is unlikely to be coincidental, at least in cortical and large subcortical ischaemic stroke [11], but patients with lacunar stroke are likely to be underrepresented in autopsy series. In the Rotterdam Scan Study, in analyses unadjusted for vascular risk factors, increased MCA flow velocities were associated with future stroke risk (subtype unspecified) [8], but all velocities were within normal limits and there was no association between the side of highest velocity and the side of stroke. It is possible that the increased velocity was simply a surrogate for higher blood pressure, which in turn was associated with stroke, in keeping with the association between increased MCA flow velocities and hypertension in the present study. Intracranial artery velocities are known to fall with age, but an incremental reduction in MCA velocity per year increase in age and per unit increase in WML score has not previously been demonstrated. The association between falling velocity and both increasing age and WML score may reflect simply a reduction in the amount of brain to supply blood to.

Atheroma in the extracranial large arteries is more common in cortical than in lacunar stroke $[17,32]$. ICA origin stenosis is unusual in patients with lacunar ischaemic stroke and unlikely to cause much lacunar stroke [30]. Our current results are consistent with this [30] and other previous studies of carotid stenosis in lacunar stroke.

If lacunar stroke is primarily nonatherothromboembolic, then secondary prevention aimed at preventing atheroma progression may not be very effective. This could explain why intensive antiplatelet treatments have not been as effective as anticipated in some secondary prevention trials of antithrombotic treatments which included large proportions of participants with lacunar stroke [33]. Alternatively, many acute stroke prevention therapies, such as blood pressure lowering, angiotensinconverting enzyme inhibitors, lipid-lowering agents and nonsteroidal antiinflammatory agents, may act on the circulation to reduce stroke through mechanisms other than simply by preventing atheroma, and therefore may be effective in preventing lacunar stroke through other mechanisms. Future studies of potential mechanisms for lacunar stroke should include controls with a different type of ischaemic stroke and be careful to standardize their vascular assessment methods.

\section{Acknowledgements}

This study was supported by the Chief Scientist Office of the Scottish Executive (CZB/4/281) (J.M.W.), the Wellcome Trust (075611) (F.D., J.M.W.), the Row Fogo Charitable Trust (AD. ROW4.35, J.M.W.) and the Scottish Funding Council through the Scottish Imaging Network, a Platform for Scientific Excellence (SINAPSE) Collaboration (funding for J.M.W. and the SFC Brain Imaging Research Centre). The MR imaging was performed in the SFC Brain Imaging Research Centre, a centre in the SINAPSE Collaboration.

References

Cerebrovasc Dis 2011;31:12-18
Davis SM, Donnan GA: Why lacunar syndromes are different and important. Stroke 2004;35:1779-1780.

2 Wardlaw JM: What causes lacunar stroke? J Neurol Neurosurg Psychiatry 2005;76:617619.

3 Wardlaw JM, Sandercock PA, Dennis MS, Starr J: Is breakdown of the blood-brain barrier responsible for lacunar stroke, leukoaraiosis, and dementia? Stroke 2003;34:806812.

4 Li H, Wong KS: Racial distribution of intracranial and extracranial atherosclerosis. J Clin Neurosci 2003;10:30-34.

5 Wong KS, Li H: Long-term mortality and recurrent stroke risk among Chinese stroke patients with predominant intracranial atherosclerosis. Stroke 2003;34:2361-2366. 
-6 Huang HW, Guo MH, Lin RJ, Chen YL, Luo Q, Zhang Y, Wong KS: Prevalence and risk factors of middle cerebral artery stenosis in asymptomatic residents in Rongqi County, Guangdong. Cerebrovasc Dis 2007;24:111115.

$>7$ Lyrer PA, Engelter S, Radu EW, Steck AJ: Cerebral infarcts related to isolated middle cerebral artery stenosis. Stroke 1997;28:10221027.

-8 Bos MJ, Koudstaal PJ, Hofman A, Witteman JCM, Breteler MMB: Transcranial Doppler hemodynamic parameters and risk of stroke: the Rotterdam study. Stroke 2007;38:24532458.

$\checkmark 9$ Baracchini C, Manara R, Ermani M, Meneghetti G: The quest for early predictors of stroke evolution: can TCD be a guiding light? Stroke 2000;31:2942-2947.

-10 Bang OY, Heo JH, Kim JY, Park JH, Huh K: Middle cerebral artery stenosis is a major clinical determinant in striatocapsular small, deep infarction. Arch Neurol 2002;59: 259-263.

$\checkmark 11$ Klein IF, Labreuche J, Lavallee PC, Mazighi M, Duyckaerts C, Hauw JJ, Amarenco P: Is moderate atherosclerotic stenosis in the middle cerebral artery a cause of or a coincidental finding in ischemic stroke? Cerebrovasc $\mathrm{Dis} 2010 ; 29: 140-145$

-12 Mazighi M, Labreuche J, Gongora-Rivera F, Duyckaerts C, Hauw JJ, Amarenco P: Autopsy prevalence of intracranial atherosclerosis in patients with fatal stroke. Stroke 2008;39: 1142-1147.

-13 Sanchez C, Guijarro C, Herreros B, Vegas A, Huelmos AI, Puras E, Belenchon JC, Barriga FJ, Lopez-Bescos L: Intracranial artery stenosis is a strong independent predictor of new ischemic events in any vascular bed in patients with clinical atherosclerosis: the AIRVAG cohort: 5 years of follow-up. Stroke 2007;38:476.

- 14 Bang OY, Joo SY, Lee PH, Joo US, Lee JH, Joo IS, Huh K: The course of patients with lacunar infarcts and a parent arterial lesion: similarities to large artery vs. small artery disease. Arch Neurol 2004;61:514-519.
15 Van Popele NM, Grobbee DE, Bots ML, Asmar R, Topouchian J, Reneman RS, Hoeks AP, van der Kulp DA, Hofman A, Witterman JC: Association between arterial stiffness and atherosclerosis: the Rotterdam Study. Stroke 2001;32:454-460.

16 Bamford J, Sandercock P, Dennis M, Burn J, Warlow C: Classification and natural history of clinically identifiable subtypes of cerebral infarction. Lancet 1991;337:1521-1526.

17 Jackson CA, Sudlow CLM: Are lacunar strokes really different? A systematic review of differences in risk factor profiles between lacunar and non-lacunar infarcts. Stroke 2005;36:891-904.

18 Wardlaw JM, Doubal F, Armitage P, Chappell F, Carpenter T, Maniega SM, Farrall A, Sudlow C, Dennis M, Dhillon B: Lacunar stroke is associated with diffuse blood-brain barrier dysfunction. Ann Neurol 2009;65: 194-202.

19 Fazekas F, Chawluk JB, Alavi A, Hurtig HI, Zimmerman RA: MR signal abnormalities at 1.5 T in Alzheimer's dementia and normal aging. AJR Am J Roentgenol 1987;149:351356.

20 MacLullich AM, Wardlaw JM, Ferguson KJ, Starr JM, Seckl JR, Deary IJ: Enlarged perivascular spaces are associated with cognitive function in healthy elderly men. J Neurol Neurosurg Psychiatry 2004;75:1519-1523.

21 Lindgren A, Staaf G, Geijer B, Brockstedt S, Stahlberg F, Holtas S, Norrving B: Clinical lacunar syndromes as predictors of lacunar infarcts: a comparison of acute clinical lacunar syndromes and findings on diffusionweighted MRI. Acta Neurol Scand 2000;101: 128-134.

22 Nabavi DG, Otis SM, Ringelstein EB: Ultrasound assessment of the intracranial arteries; in Zwiebel WJ, Pellerito JS (eds): Introduction to Vascular Ultrasonography. Philadelphia, Elsevier Saunders, 2005, pp 225-250.

23 Potter G, Doubal F, Jackson C, Sudlow C, Dennis M, Wardlaw J: Associations of clinical stroke misclassification (clinical-imaging dissociation) in acute ischemic stroke. Cerebrovasc Dis 2010;29:395-402.

-24 Zanette EM, Fieschi C, Bozzao L, Roberti C, Toni D, Argentino C, Lenzi GL: Comparison of cerebral angiography and transcranial Doppler sonography in acute stroke. Stroke 1989;20:899-903.
25 Demchuk AM, Christou I, Wein TH, Felberg RA, Malkoff M, Grotta JC, Alexandrov A: Specific transcranial Doppler flow findings related to the presence and site of arterial occlusion. Stroke 2000;31:140-146.

26 Allendoerfer J, Goertler M, von Reutern GM: Prognostic relevance of ultra-early Doppler sonography in acute ischaemic stroke: a prospective multicentre study. Lancet Neurol 2006;5:835-840

27 Doubal FN, Rumley A, Lowe GD, Dennis MS, Wardlaw JM: Coagulation activation, fibrinolysis and inflammation in ischaemic stroke subtypes. Cerebrovasc Dis 2008; 25(suppl 2):125

28 Wong KS, Li H, Chan YL, Ahuja A, Lam WW, Wong A, Kay R: Use of transcranial Doppler ultrasound to predict outcome in patients with intracranial large-artery occlusive disease. Stroke 2000;31:2641-2647.

-29 Lee PH, Oh SH, Bang OY, Joo SY, Joo IS, Huh $\mathrm{K}$ : Infarct patterns in atherosclerotic middle cerebral artery versus internal carotid artery disease. Neurology 2004;62:1291-1296.

$>30$ Mead GE, Lewis SC, Wardlaw JM, Dennis MS, Warlow CP: Severe ipsilateral carotid stenosis and middle cerebral artery disease in lacunar ischaemic stroke: innocent bystanders? J Neurol 2002;249:266-271.

-31 Mead GE, Wardlaw JM, Dennis MS, Lewis SC, Warlow CP: Relationship between pattern of intracranial artery abnormalities on transcranial Doppler and Oxfordshire Community Stroke Project clinical classification of ischemic stroke. Stroke 2000;31:714-719.

32 Jackson CA, Hutchison A, Dennis MS, Wardlaw JM, Lindgren A, Norrving B, Anderson CS, Hankey GJ, Jamrozik K, Broadhurst RJ, Appelros P, Sudlow CLM: Differing risk factor profiles of ischemic stroke subtypes: evidence for a distinct lacunar arteriopathy? Stroke 2010;41:624-629.

33 Diener HC, Bogousslavsky J, Brass LM, Cimminiello C, Csiba L, Kaste M, Leys D, Matias-Guiu J, Rupprecht HJ, MATCH investigators: Aspirin and clopidogrel compared with clopidogrel alone after recent ischaemic stroke or transient ischaemic attack in highrisk patients (MATCH): randomised, double-blind, placebo-controlled trial. Lancet 2004;364:331-337. 